\title{
An analysis of invitations for article submission received via emails
}

\author{
SANDEEP B BAVDEKAR, SHRUTI SAHA, URMLA M THATTE, NITHYA J GOGTAY
}

\begin{abstract}
Predatory journals charge publication fees from authors and publish without an adequate peer review, and often do not provide editorial and/or publishing services. Our objective was to evaluate e-mail solicitations received by authors in a defined time period to identify attributes of these solicitations as a metric to identify legitimacy of the journal. All e-mails seeking article submission received between January 1 and September 30, 2019, were evaluated. Each e-mail along with its respective webpage was evaluated for the journal's and publisher's names, mention of peer review, any assurance of publication, a mention of article processing charges (APC), composite invites [in the email] and mention of peer review, the presence and functionality of archives, presence of manuscript management tab, mention of APC [on the webpage]. Descriptive statistics were used for the analysis. Of the 135 e-mails screened, 100 were finally included in the analysis. We found that $72 \%$ of the journals and/ or publishers were included in Beall's list. According to our criteria, a total of $85 \%$ of the solicitations were from journals that we identified as "presumed predatory". Our study has identified assurance of publication, rapid turnaround time, ambiguous information in the email and webpage, false claims of indexing as some descriptors which may help young authors and researchers assess a journal's legitimacy.
\end{abstract}

Keywords: Predatory journals, Article processing charges (APC), open access journals, indexed journals, assurance of publication

\section{Background and rationale}

Predatory journals and predatory publishing present a major

Author: Sandeep B Bavdekar (sandeep.bavdekar@gmail.com) Surya Hospitals, Mumbai, INDIA; Shruti Saha (shruti.tia@gmail.com), Department of Clinical Pharmacology, Seth GS Medical College \& KEM Hospital, Parel, Mumbai 400012 INDIA; Urmila M Thatte (urmilathatte@gmail.com) Department of Clinical Pharmacology, Seth GS Medical College \& KEM Hospital, Parel, Mumbai 400012 INDIA; Nithya J Gogtay (corresponding author - njgogtay@hotmail.com), Department of Clinical Pharmacology, Seth GS Medical College \& KEM Hospital, Parel, Mumbai 400012.

To cite: Bavdekar SB, Saha S, Thatte UM, Gogtay NJ. An analysis of invitations for article submission received via emails. Indian J Med Ethics. Published online on August 10, 2021. DOI: 10.20529/IJME.2021.060

Manuscript Editor: Vijayaprasad Gopichandran

Peer Reviewers: Two anonymous peer reviewers

( I Indian Journal of Medical Ethics 2021 challenge to science and scholarly communication. This problem has grown exponentially in recent years. While multiple attributes can be accorded to these journals, the description below covers the myriad aspects of the deception adopted by these journals and their publishers (1):

Predatory journals and publishers are entities that prioritize self-interest at the expense of scholarship and are characterized by false or misleading information, deviation from best editorial and publication practices, a lack of transparency, and/or the use of aggressive and indiscriminate solicitation practices...

Publications such as these have serious ethical implications that include, among others, academic deception, wasted research finding and undermining of public confidence in published literature. Jeffrey Beall, a librarian and Associate Professor at the University of Colorado, Denver, USA, published a list of such journals and publishers (Beall's list) in 2010 which was shut down in $2017(2,3,4)$. This list is periodically updated and the last update of the list was in March 2021. Others have also put forward criteria to help identify predatory journals $(5,6,7,8)$.

Many journals (whether "predatory" or legitimate) solicit manuscripts from potential authors via e-mails. While several studies have focused on the problem of predatory journals, very few have actually analysed how authors may be tricked or lured into publishing in them (9). E-mails received from predatory journals or publishers often come with a sense of urgency and an assurance of a rapid turnaround time. An analysis of these e-mail solicitations (electronic submission requests) could potentially help to identify the characteristics of these journals and to assess whether or not they may be predatory.

The present study was thus envisaged with the primary objective of evaluating e-mail solicitations received by authors in a defined time period to identify attributes of these solicitations as a metric to determine the legitimacy of the journal.

\section{Methods}

\section{Ethics}

The study was conducted after the protocol was exempted from review by the Institutional Ethics Committee (IEC) [EC / OA-73/2019] on June 7,2019. 


\section{Time period and eligibility}

All e-mails received by one of the authors from January 1, 2019, to September 30, 2019, were evaluated. These e-mails were retrieved from both the general inbox and the spam folder. Inclusions were e-mail solicitations with or without any other request such as an invitation to serve on the editorial board in addition to requesting a manuscript.

Duplicate e-mails, e-mails from non-medical journals (eg engineering, agriculture, astronomy), e-mails from publishers regarding multiple journals, those from conference organisers or book publishers, and e-mails containing invitations other than article solicitation (eg invitation as editor) were excluded so as to retain homogeneity and focus on individual journals in the medical speciality alone.

\section{Study procedure}

The study consisted of two parts - evaluation of the e-mail followed by evaluation of the journal's webpage done independently by SS and SBB without consulting each other. In the first stage, we reviewed the e-mails looking at features in the email called descriptors henceforth, such as the journal's and the publisher's name, mention of peer review, any assurance of publication, a mention of article processing charges (APC), composite invites for example, invitation to serve on the editorial board or join as a reviewer, in addition to submitting a manuscript and any additional information mentioned in the email not covered under descriptors. In the second stage, we looked at the webpage for mention of peer review, the presence and functionality of archives and checked for a manuscript management tab, mention of APC, the name of the publisher [only if missing in the e-mail], and any additional information. We also specifically looked for a statement that the journal complied with the Medical Council of India (MCl) and University Grants Commission (UGC) publication norms for promotion.

The journal webpage was accessed either via the link provided in the e-mail or via a Google search. The information gathered from the e-mail and the webpage was then compared.

\section{Assessment criteria}

We checked if the journals and their publishers featured in Beall's list. We also checked if these journals were included in the Directory of Open Access Journals (DOAJ) [directory], PubMed [interface], MEDLINE [Index], or PubMed Central (PMC) [Repository]. The DOAJ was checked because predatory journals and publishers exploit the open access model for article processing charges (APC).

\section{Classification of journals and their publishers}

After completion of the two parts of the study, all journals and their publishers were classified as either "presumed predatory" or "presumed legitimate" based on the following criteria that covered descriptors in both the e-mail and the webpage. While there exist criteria in literature for classifying journals as potentially predatory, for the purpose of this study, we developed these criteria based on consensus for classifying an e-mail as belonging to a presumed predatory journal.These included:

- assurance of publication or rapid turnaround time (any duration less than 30 days),

- false claims of indexing (eg DOAJ, PubMed, Scopus) and

- discrepancy in information provided (between the email and the journal website and also within the webpage).

If the email fulfilled one or more criteria, the journal described in the email was classified as a "presumed predatory" journal. As a corollary, e-mails that did not meet these criteria were classified as 'presumed legitimate".

\section{Outcome measure}

The proportion of presumed predatory and presumed legitimate journals as a percentage of the total emails received formed the primary outcome measure.

\section{Statistical analysis}

Both descriptive and inferential statistics were applied to the data. Quantitative data (such as the number of journals or publishers) were summated, while categorical variables were presented as proportions. Inferential statistics were computed using the Chi-square test for categorical data which was applied to assess between-group differences for presumed predatory and presumed legitimate journals. All analyses were done at 5\% significance using SPSS version 25 and MS Excel 2016.

\section{Results \\ E-mails}

A total of 135 e-mails were received during the study period, of which 35 (25.93\%) were excluded (para 3 in Methods ) and the remaining 100 e-mails formed the final sample that was analysed.

\section{Analysis of descriptors}

The e-mails described a total of 100 journals and 50 publishers. Forty e-mails mentioned peer review, twelve gave an assurance of publication while 18 mentioned APC. A total of 13 e-mails had composite invitations

\section{Analysis of additional information}

Fifteen e-mails provided assurance of a rapid turnaround time (median [range] 10 days [1-30]). Fourteen e-mails mentioned discounts on APC for a limited duration, while 22 e-mails mentioned the impact factor of the journal. Thirty-three emails mentioned the last date of manuscript submission (for consideration for the next issue) while 10 e-mails listed indexing agencies where the journal was indexed. Twenty e- 
mails stated that a "best article" award and certificate would be given to the author. Seventy-six e-mails provided a link to the journal webpage but of these 76 e-mails, the link was non-functional in seven. Five e-mails made a statement of the journal being compliant with the $\mathrm{MCl}$ and/or UGC latest publication norms for promotion. None of these 5 emails mentioned APC. Three of these five e-mails gave an assurance of publication.

\section{Analysis of the webpage for descriptors}

All the journals mentioned in the e-mails had a searchable webpage; however, the link for the webpage was provided in only 76 of the e-mails. We found that 98/100 mentioned peer review, 81 had functional archives, 6 had no archives and 13 either had non-functional or poorly designed archives. Only 22 journals mentioned in the e-mails had a functional manuscript management system. Eighty-two journals mentioned APC on the webpage.

\section{Additional information obtained from the webpages}

We also noted that of the 98 journals that mentioned peer review, 5 journals had at the most two reviewers mentioned on their webpage. When claims of indexing (DOAJ/ PubMed) were investigated, we found that $31 / 100$ journals falsely claimed that they were indexed. Fifteen journals promised a rapid turn-around time instead of assurance of publication. We also observed that 25/100 journals would charge for withdrawal of a manuscript at any stage after submission. Thirty-five journals had different APCs based on either nature/ length of manuscript, or nationality of authors, or number of authors.

\section{Comparison of information provided in e-mail and webpage}

Only 40 e-mails mentioned peer review, while 98 journals mentioned peer review on the webpage. In the e-mail invitation, 83 e-mails did NOT mention APC, while, on the webpage only 18 did not mention APC. It was noted that in $81 / 100$ journals there were discrepancies in the information provided in the e-mail and webpage, or within the webpage.

\section{Beall's list}

In all, a total of 72 [either journal or publisher] had their names listed in Beall's list. Of these, 10 were journals, 58 were publishers, and for 4 both the journal and publisher names were listed.

\section{Indexing of journals}

Fifteen of the 100 were PubMed searchable; two were indexed with MEDLINE, 14 were found in PubMed Central (PMC), and only 1 was listed in DOAJ. Of the 15 (80\%) PubMed searchable journals, 12 were found in Beall's list.

\section{Final classification of journals mentioned in e-mails as} presumed predatory or other journals

Using our pre-defined criteria, we classified $85 \%$ of the e-mails as coming from a "presumed predatory" journal. The distribution of attributes across presumed predatory journals is described in Tables 1 and 2.

\section{Discussion}

Our audit of one hundred e-mail solicitations from journals/ publishers seeking manuscript submissions showed [after

Table 1: Distribution of descriptors across journals presumed predatory and presumed legitimate

\begin{tabular}{|c|c|c|}
\hline $\begin{array}{l}\text { Descriptor in e-mail/ journal or } \\
\text { publisher webpage }\end{array}$ & $\begin{array}{l}\text { Presumed } \\
\text { predatory } \\
(\mathrm{N}=85) \\
\mathrm{n}(\%)\end{array}$ & $\begin{array}{l}\text { Presumed } \\
\text { legitimate } \\
(\mathrm{N}=15) \\
\mathrm{n}(\%)\end{array}$ \\
\hline Peer review $(n=40)$ & $35(41)$ & $5(33)$ \\
\hline Assurance of publication $(n=12)$ & $12(14)$ & $0(0)$ \\
\hline Rapid turnaround time $(n=15)$ & $15(18)$ & $0(0)$ \\
\hline Mention of APC $(n=82)$ & $69(81)$ & $13(87)$ \\
\hline Discount in APC $(n=5)$ & $4(5)$ & $1(7)$ \\
\hline Composite invites $(n=13)$ & $8(9)$ & $5(33)$ \\
\hline Mention of impact factor $(n=22)$ & $21(25)$ & $1(7)$ \\
\hline Mention of last date of submission $(n=33)$ & $30(35)$ & $3(20)$ \\
\hline Link to journal webpage $(n=76)$ & $64(75)$ & $12(80)$ \\
\hline Functional archive $(\mathrm{n}=81)$ & $71(83)$ & $10(67)$ \\
\hline Functional MMS $(n=22)$ & $19(22)$ & $3(20)$ \\
\hline $\begin{array}{l}\text { Certificate of publication/ best article } \\
\text { award }(n=9)\end{array}$ & $9(10)$ & $0(0)$ \\
\hline False claims of indexing $(n=31)$ & $31(36)$ & $0(0)$ \\
\hline
\end{tabular}

APC: Article processing charges; MMS: Manuscript management system

Table 2: Distribution of of the three attributes in the e mails received [N=100]

\begin{tabular}{|l|l|l|l|}
\hline Attributes & $\begin{array}{l}\text { Presumed } \\
\text { predatory } \\
(\mathrm{n}=85) \\
\mathrm{n}(\%)\end{array}$ & $\begin{array}{l}\text { Presumed } \\
\text { legitimate } \\
(\mathrm{n}=15) \\
\mathrm{n}(\%)\end{array}$ & p-value \\
\hline $\begin{array}{l}\text { Assurance of publication } \\
\text { or of rapid turnaround } \\
\text { time }\end{array}$ & $27 / 85(32)$ & $0 / 15(0)$ & $<0.001$ \\
\hline False claims of indexing & $31 / 85(36)$ & $0 / 15(0)$ & 0.01 \\
\hline $\begin{array}{l}\text { Discrepancy of } \\
\text { information }\end{array}$ & $81 / 85(14)$ & $0 / 15(0)$ & $<0.001$ \\
\hline $1 / 3$ attributes present & $85 / 85(100)$ & $0 / 15(0)$ & \\
\hline $2 / 3$ attributes present & $48 / 85(56)$ & $0 / 15(0)$ & \\
\hline $3 / 3$ attributes present & $6 / 85(7)$ & $0 / 15(0)$ & \\
\hline
\end{tabular}

Between group comparison done using the chi- square test at $5 \%$ significance 
analysis of the e-mail and the corresponding webpage] that a majority [85\%] of solicitations were from journals presumed predatory in nature.

The difficulty in defining predatory journals lies in the fact that features of legitimate and predatory journals overlap. Our classification of journals and publishers contained in the e mail solicitations as potentially predatory was based on three criteria identified after a literature search as there exist no clear-cut criteria for their classification/ identification. Cabell's and Beall's criteria may not be easy to use for the average researcher as the former has 65 and the latter 14 criteria $(2,5,6)$. Also, researchers tend to primarily focus on journals and rarely on publishers and Cabell's and Beall's criteria also include elements for classifying a publisher as potentially predatory. In addition, the lists are not infallible and are updated only periodically. Thus, our criteria may help raise "red flags" for researchers and authors who receive these e-mail solicitations.

In legitimate journals, manuscripts undergo a formal peer review process following which they are either accepted for publication or rejected. This peer review process is time consuming and may take up to several weeks. Thus, journals that follow an authentic peer review process cannot provide an assurance of publication or a short turn-around time for the submitted manuscripts $(10,11)$. False claims of indexing and contradictions in the information provided in emails and journal/ publisher webpages indicate an obvious attempt to entice manuscript submission.

It is common practice for several Open Access [OA] journals to charge APC $(12,13)$. This practice is necessary, as the journals/ publishers do not charge readers for access and the cost of publication has to be borne by someone. This information is important for the contributor, as the expense involved will be one of the factors that an author would consider while choosing the journal. We found that 83 emails did not mention APC. However, $65 / 83$ of these journals mentioned APC on the webpage suggesting that they wished to hide this information in the initial e-mail. We found that $61 / 65$ of these journals were on Beall's list. Many e-mails also offered APC discounts. The language of these discounts did not indicate a genuine discount offered for LMICs by legitimate journals. For example, the discounts always had a deadline for submission and this discount was not mentioned on the webpage. Thus, it is not clear if these are genuine discounts or because the journal is facing a shortage of papers.

We found that some journals charge fees (usually the amount is unspecified) for manuscript withdrawal, which makes it difficult for young researchers who have to spend this money first before they can submit their manuscript to another journal.

The existence of a peer-review process, an editorial board, inclusion in an indexing database, recognised publishing standards and transparency about charges levied are the attributes of reputable journals (14). However, authors cannot check if the journal undertakes a peer review, whether the editorial board exists at all, and if it follows recognised publishing standards. Hence, we used proxy descriptors (number of reviewers listed on the webpage, functioning archives, functioning manuscript management system) to determine the journal's/ publisher's commitment to quality and willingness to incur expenditure to ensure that the scientific material is digitally preserved for future researchers.

We found a small percentage of journals making a statement that they followed the MCl's and/or the UGC's norms of publication. This is relevant only to authors in India, where academicians' promotions to a higher post depend on publication of research papers in " $\mathrm{MCl}$ and/ or UGC approved journals" (15). This is again a red flag as this is an obvious attempt to entice Indian authors to submit manuscripts for economic gains.

Our finding of $12 \%$ potentially predatory journals being PubMed-searchable is worrisome as it is a common assumption that "presence in PubMed" implies that a journal is legitimate. Indexing with PubMed requires a two-year history of publication along with following guidelines for editorial and publication policies laid down by the International Committee of Medical Journal Editors (ICMJE) and the Committee on Publication Ethics (COPE). Despite this, the fact that predatory journals, at times, "leak" into PubMed has been noticed earlier $(16,17)$ with calls for the National Library of Medicine (NLM) to tighten its criteria and processes. Researchers need to make the distinction between "PubMed searchable" versus "MEDLINE indexed" both of which are separate entities albeit used interchangeably erroneously.

Very few authors have studied e-mail solicitations received. None of these authors have attempted to compare the descriptors in the invitations from predatory and other journals, making our study unique. Authors have noted that many times these invitations are received from relatively new journals (9), and that most of these journals charge lower article processing fees compared to reputed journals (9). Predatory journals have also chosen not to register with DOAJ despite being open access journals and thus do not have a journal metric (18).

Our study was limited by the small sample size, the short duration, and the use of a single tool (Beall's list, as other tools were not freely available). In addition, the three criteria that we used to classify a journal as potentially predatory were arrived at by consensus. An e-mail solicitation that does not meet these criteria has been classified by us as potentially legitimate. As the criteria are not watertight, we recommend that authors and particularly young authors vet the journal for themselves prior to making a submission.

In summary, an overwhelming majority of e-mails soliciting manuscripts from potential authors are sent by presumed predatory journals. Young researchers may get enticed to 
submit their valuable research articles to presumed predatory journals. Predatory journals are the scourge of scientific literature as they cause damage to individual scientists, and to science itself.

Authors should first note that it is rare for reputed journals and those indexed in Medline or DOAJ to send personalised invitations to prospective authors inviting manuscript submission. Some journals may request reviewers to write a commentary or editorial on the article that they have reviewed (8). Authors should follow the principle of

to make their own decision regarding the legitimacy of the journal. They should scrutinise the journal and publisher webpages and look for discrepancies and contradictions in the information provided. Our study has found some attributes/ descriptors to identify presumed predatory journals. Researchers may benefit by using these descriptors/ attributes. However, finally, it is only individual integrity that will help in breaking the vicious circle of predatory journal publishing.

\section{References}

1. Grudniewicz A, Moher D, Cobey KD, Bryson GL, Cukier S, Allen K, et al. Predatory journals: no definition, no defence. Nature. 2019 Dec11; 576(7786): 210-12.

2. Beall J. Criteria for determining predatory open-access publishers. 2015[cited 2019 May 25]. Available from:https://beallslist.weebly.com/ uploads/3/0/9/5/30958339/criteria-2015.pdf

3. Beall's list of potential predatory journals and publishers. Date unknown [cited 2021 Jan 27]. Available from: https://beallslist.net/ standalone-journals/.

4. What is Beall's list? Why was it shut down? Date unknown [cited 2021 Jun 1]. Available from: https://predatory-publishing.com/what-is- bealls-list-why-was-it-shut-down/.

5. Das S, Chatterjee S. Cabell's blacklist: a new way to tackle predatory journals. Indian J Psychol Med. 2018 Mar-Apr; 40(2): 197-8. DOI: 10.4103/ijpsym.ijpsym_290_17

6. Cabell D. Cabell's Predatory Reports Criteria. 2019 Mar 13[cited 2019 May 25]. Available from: https://www2.cabells.com/blacklist-criteria.

7. Eriksson S, Helgesson G. The false academy: predatory publishing in science and bioethics. Med Health Care Philos. 2017; 20(2):163-70.

8. Kakamad FH, Mohammed SH, Najar KA, Qadr GA, Ahmed JO, Mohammed KK, et al. Kscien's list; a new strategy to hoist predatory journals and publishers. Int J Surg Open. 2019; 17: 5-7.

9. Ball S, Kopel J, Alexander R, Nugent K. Solicitation for article submission by electroni journals. Proc (Bayl Univ Med Cent). 2018 Sep 24;31(4):443-6. Doi: 10.1080/08998280.2018.1498725.

10. Gades NM, Toth LA. How to avoid becoming easy prey for "predatory" journals and why it matters. Comp Med. 2019 May 1;69(3):164-6.

11. Shamseer L, Moher D, Maduekwe O, Turner L, Barbour V, Burch R, et al. Potential predatory and legitimate biomedical journals: can you tell the difference? A cross- sectional comparison. BMC Med. 2017 Mar 16; 15(1):28. Doi: 10.1186/s12916-017-0785-9.

12. Shen C, Björk BC. 'Predatory' open access: a longitudinal study of article volumes and market characteristics. BMC Med. 2015 Oct 1; 13(1):230-44. Doi: 10.1186/s12916-015-0469-2.

13. Björk BC, Solomon D. Open access versus subscription journals: a comparison of scientific impact. BMC Med. 2012 Jul 17;10(1):73-82. Doi: 10.1186/1741-7015-10-73.

14. Happe LE. Distinguishing predatory from reputable publishing practices. J Manag Care Spec Pharm. 2020 Aug; 26(8):956-60. Doi: 10.18553/jmcp.2020.26.8.956.

15. Aggarwal R, Gogtay N, Kumar R, Sahni P. The revised guidelines of the Medical Council of India for academic promotions: Need for a rethink. Indian J Urol. 2016 Jan-Mar; 32(1):1-4. Doi: 10.4103/09701591.173117.

16. Manca A, Moher D, Cugusi L, Dvir Z, Deriu F. How predatory journals leak into PubMed. CMAJ. 2018 Sep 4;190(35):E1042-4. Doi: 10.1503/ cmaj.180154.

17. Wood KE, Krasowski MD. Academic E-Mail overload and the burden of "Academic Spam". Acad Pathol. 2020 Jan 21;7:2374289519898858. Doi: 10.1177/2374289519898858.

18. Moher D, Srivastava A. You are invited to submit... BMC Med. 2015 Aug 4;13:180. Doi: 10.1186/s12916-015-0423-3. 